\title{
ANALISIS RISIKO PRODUKSI USAHA TANI KARET UNGGUL DAN KARET LOKAL DI DESA SEKURA, KECAMATAN TELUK KERAMAT, KABUPATEN SAMBAS
}

\author{
RISK ANALYSIS OF FARMING PRODUCTION SUPERIOR RUBBER AND LOCAL \\ RUBBER IN THE SEKURA VILLAGE TELUK KERAMAT DISTRICT OF SAMBAS \\ REGENCY
}

Suryani, Novira Kusrini, dan Imelda

Program Studi Agribisnis Fakultas Pertanian Universitas Tanjungpura, Pontianak Jln. Prof. Dr. Hadari Nawawi, Pontianak, 78124, Indonesia.

Email: suryanipnk@gmail.com

\begin{abstract}
ABSTRAK
Penelitian ini bertujuan untuk Menganalisis seberapa besar Risiko Produksi Pada Kelompok (1) Umur Tanaman 15 dan 16 Tahun, Kelompok (2) Umur Tanaman 17 dan 18 Tahun, dan Kelompok (3) Umur Tanaman 20 Tahun Usahatani Karet Unggul dan Karet Lokal di Desa Sekura Kecamatan Teluk Keramat Kabupaten Sambas dan untuk Membandingkan Risiko Produksi Usahatani Karet Unggul dan Karet Lokal di Desa Sekura Kecamatan Teluk Keramat Kabupaten Sambas. Pada penelitian ini menggunakan metode survey dengan lokasi penelitian di Desa Sekura Kecamatan Teluk Keramat Kabupaten Sambas. Lokasi penelitian ditentukan dengan sengaja (purposive), populasi dalam penelitian ini adalah petani karet unggul dan petani karet lokal sebanyak 84 orang dengan 42 orang petani karet unggul dan 42 orang petani karet lokal. Variabel penelitian meliputi Risiko produksi usahatani karet unggul dan karet lokal. Tekhnik analisis data yang digunakan adalah koefisian variasi (CV).

Hasil penelitian dari ketiga kelompok umur tanaman karet unggul maupun lokal yaitu umur 15 dan 16 tahun, 17 dan 18 tahun, dan 20 tahun. Ternyata yang paling berisiko adalah pada umur 20 tahun dengan nilai CV $1=0,47>\mathrm{CV} 2=0,37$. dan produksi yang dihasilkan usahatani karet unggul lebih besar daripada produksi karet lokal. Risiko produksi usahatani karet unggul lebih besar atau sama dengan risiko produksi karet lokal dengan nilai CV $1=0,36 \geq \mathrm{CV} 2=0,32$
\end{abstract}

Kata Kunci : Risiko Produksi, Usahatani, Karet Unggul, Karet Lokal

\section{ABSTRACT}

The purpose of This study is to analyze how much the risk of production for the group (1) the age of plant is 15 and 16 years, group (2) the age of plant is 17 and 18 years, and group (3) the age of plant is 20 years. Superior rubber and Local rubber farm in the Sekura Village Teluk Keramat District of Sambas regency. Compare the risks of farm production about Superior Rubber and Local Rubber Respondents in the Sekura Village Teluk Keramat District of Sambas regency. This study is using the survey method with research sites in the Sekura village Teluk Keramat District of Sambas regency. Research location is determined intentionally (purposive), the population in this study are the superior rubber farmers and the local rubber farmers were 84 people with 42 superior rubber farmers and 42 local rubber farmers. The research variables include the risk of superior rubber farm and local rubber production. Data analysis technique using a Coefficient of variation (cv) and independent T-test. 
This results of three age groups superior rubber and local rubber that is 15 and 16 years, 17 and 18 years, and than 20 years. It turns out that most risk was at the age of 20 years with a value $C V 1=0,47>C V 2=0,37$, and the resulting production superior rubber is greater than the production local rubber. Superior rubber farm production risk is greater or equal $(\geq)$ to the risk of local rubber production value of $C V 1=0,36 \geq C V 2=0,32$.

\section{Keywords: Production Risk, Farming, Superior Rubber, Local Rubber.}

\section{PENDAHULUAN}

Tanaman karet (Hevea Brasiliensis) sangat penting dikembangkan karena memiliki beberapa keunggulan dibandingkan dengan komoditas lainnya. Yaitu dapat tumbuh pada berbagai kondisi dan jenis lahan, serta masih mampu dipanen hasilnya meskipun pada lahan tanah yang tidak subur, mampu membentuk ekologi hutan yang pada umumnya terdapat pada daerah lahan kering beriklim basah, sehingga karet cukup baik menanggulangi lahan kritis, dapat memberikan pendapatan harian bagi petani yang mengusahakannya.

Secara umum dalam berusahatani selalu dihadapkan pada masalah risiko dan ketidakpastian. Masalah iklim seperti musim kemarau panjang, hujan yang tidak menentu, masalah serangan penyakit tanaman yang sulit diduga sebelumnya, masalah bencana alam seperti banjir, gempa dan letusan gunung merapi, masalah kekurangan air irigasi atau air hujan atau masalah lain adalah contoh betapa kehidupan tanaman ini sebenarnya tunduk pada aspek risiko dan ketidakpastian, (Soekartawi dalam Abdullah, 1993). Dengan demikian usahatani karet unggul dan karet lokal juga dihadapkan pada masalah risiko iklim, hama penyakit dan produksi yang pada akhirnya berpengaruh terhadap pendapatan.

Khususnya Desa Sekura yang terletak di Kecamatan Teluk Keramat, daerah ini merupakan daerah perkebunan karet rakyat yang menjadi andalan dan sumber pendapatan terbesar bagi masyarakat sekitar. Tujuan akhir dari suatu proses produksi adalah menghasilkan produk untuk dipasarkan atau dijual dengan harapan mendapatkan imbalan berupa penghasilan atau keuntungan yang memadai. Namun untuk mencapai tujuan akhir tersebut mengalami beberapa kendala diantaranya kendala produksi, hal ini disebabkan karena perawatan yang kurang efisien dan pemberian pupuk ala kadarnya saja mengingat harga pupuk yang mahal maka akan menimbulkan risiko dalam produksi karena dapat mengurangi lateks pada tanaman karet.

Oleh sebab itu analisis risiko produksi usahatani karet unggul dan karet lokal perlu dilakukan sehingga dapat diambil keputusan untuk menghindari atau mengurangi risiko yang akan dihadapi oleh petani dalam mengusahakannya.

\section{METODE PENELITIAN}

Metode yang digunakan dalam penelitian ini adalah menggunakan metode survei. Penelitian ini dilaksanakan pada bulan Maret 2015 di Desa Sekura Kecamatan Teluk Keramat Kabupaten Sambas.

\section{Populasi}

Populasi yang menjadi objek dalam penelitian ini adalah petani karet unggul dan petani karet lokal. Populasi dalam penelitian ini berjumlah $550 \mathrm{KK}$ yang terdiri atas petani karet unggul $275 \mathrm{KK}$ dan petani karet lokal berjumlah $275 \mathrm{KK}$

\section{Sampel}

Dewi (1998) mengatakan bahwa dalam menentukan besaran ukuran sampel dalam penelitian dapat menggunakan metode Slovin, dengan rumus sebagai berikut :

$$
n=\frac{N}{1+N e^{2}}
$$

Keterangan :

$\mathrm{n}=$ jumlah sampel

$\mathrm{N}=$ jumlah populasi

$\mathrm{e}=$ Taraf kesalahan (error)

Pengambilan sampel 84 orang yang merupakan petani karet unggul dan karet lokal.

\section{Jenis dan Sumber Data}

Data primer adalah data yang diperoleh melalui observasi dan wawancara langsung dengan petani menggunakan alat bantu daftar 
pertanyaan (kuisioner) untuk memperoleh informasi terkait dengan risiko produksi karet unggul dan karet lokal. Dan data sekunder yang diambli dari intansi terkait dengan penelitian ini.

\section{Variabel Penelitian}

Variabel yang digunakan untuk menganalisis risiko produksi usahatani karet unggul dan karet lokal di Desa Sekura Kecamatan Teluk Keramat Kabupaten Sambas yaitu jumlah produksi karet sheet selama 1 (satu tahun) yaitu di tahun 2015 yang dipanen dalam satuan kilogram.

\section{ANALISIS DATA}

Alat analisis yang digunakan dalam penelitian ini yaitu :

1. Untuk mengetahui risiko produksi pada kelompok (1) umur tanaman 15 dan 16 tahun, kelompok (2) pada umur tanaman 17 dan 18 tahun dan kelompok (3) umur tanaman 20 tahun Usahatani Karet Unggul dan Karet Lokal di Desa Sekura Kecamatan Teluk Keramat Kabupaten Sambas dengan alat ukur koefisien vaiansi.

2. Untuk menguji perbedaan Risiko Produksi Responden Usahatani Karet Unggul dan Karet Lokal. Sugiono (2014) menjelaskan Uji Independen T-test merupakan analisis statistik yang dapat digunakan untuk menguji hipotesis komparatif, khususnya perbedaan rata-rata dua kelompok sampel yang tidak saling berhubungan. Perbedaan risiko produksi pada usahatani karet unggul dan karet lokal dilakukan dengan uji beda rata-rata dengan taraf signifikan 0,05. Adapun rumus T-test adalah sebagai berikut:

$$
\mathrm{t}=\frac{\overline{X_{1}}-\bar{X}_{2}}{\sqrt{\frac{\left(n_{1}-1\right) S_{1}^{2}+\left(n_{2}-1\right) S_{2}^{2}\left(\frac{1}{n_{1}}+\frac{1}{n_{2}}\right)}{n_{1}-1}}}
$$

dimana :

$$
\begin{aligned}
& S_{1}^{2}=\frac{\left(x_{1}-\bar{x}_{1}\right)^{2}}{\left(n_{1}-1\right)} \\
& S_{2}^{2}=\frac{\left(x_{2}-\bar{x}_{2}\right)^{2}}{\left(n_{2}-1\right)}
\end{aligned}
$$

Keterangan :

$\mathrm{n}_{1}=$ Jumlah sampel petani karet unggul

$\mathrm{n}_{2}=$ Jumlah sampel petani karet lokal

\author{
$\bar{X}_{1}=$ Rata-rata risiko produksi \\ usahatani karet unggul \\ $\bar{X}_{2}=$ Rata-rata risiko produksi \\ usahatani karet lokal \\ $\mathrm{X}_{1}=$ Besarnya risiko produksi karet \\ unggul \\ $\mathrm{X}_{2}=$ Besarnya risiko produksi karet \\ lokal \\ $S_{1}^{2}=$ Varians dari risiko produksi \\ usahatani karet unggul \\ $S_{2}^{2}=$ Varians dari risiko produksi \\ usahatani karet lokal.
}

\section{HASIL DAN PEMBAHASAN}

Hasil penelitian Analisis Risiko Produksi Usahatani Karet Unggul dan Karet Lokal di Desa Sekura Kecamatan Teluk Keramat Kabupaten Sambas adalah risiko produksi pada kelompok (1) umur tanaman 15 dan 16 tahun, kelompok (2) pada umur tanaman 17 dan 18 tahun dan kelompok (3) umur tanaman 20 tahun. Dapat dilihat pada tabel.1 berikut ini.

Tabel 1. Analisis Perbandingan Risiko Produksi Karet Unggul dan Karet Lokal Kelompok 1, Kelompok 2, dan Kelompok 3

\begin{tabular}{lccc}
\hline \multirow{2}{*}{ Keterangan } & \multicolumn{3}{c}{ Produksi karet sheet $(\mathrm{Kg})$} \\
& $\mathrm{K} 1$ & $\mathrm{~K} 2$ & $\mathrm{~K} 3$ \\
\hline Jumlah & 21639.6 & 18174.7 & 17941.8 \\
Rata-rata & 772.84 & 649.09 & 640.77 \\
Standar deviasi & 346.74 & 355.39 & 365.28 \\
Koefisien & & & \\
Variasi (CV) & 0.44 & 0.54 & 0.57 \\
\hline
\end{tabular}

Sumber data : Analisis Data Primer, 2015

Keterangan : Umur tanaman K1 $=15$ dan 16 tahun, $\mathrm{K} 2=17$ dan 18 tahun, K3 $=20$ tahun

Dari ketiga kelompok umur tanaman karet yaitu, kelompok 1 umur tanaman 15 dan 16 tahun, kelompok 2 umur tanaman 17 dan 18 tahun, dan kelompok 3 umur tanaman 20 tahun, yang paling berisiko adalah pada kelompok 3 yaitu pada umur tanaman 20 tahun. Hal ini disebabkan oleh semakin tua umur tanaman karet semakin mudah terserang hama penyakit. Hama yang sering menyerang tanaman karet unggul maupun lokal di Desa Sekura adalah hama anai-anai atau rayap (Coptotermes curvignatus). 
Risiko produksi karet unggul lebih besar atau sama dengan risiko produksi karet lokal, dapat dilihat pada tabel.1 berikut ini.

Tabel 2. Analisis Perbandingan Risiko Produksi Karet Unggul dan Karet Lokal

\begin{tabular}{lcc}
\hline \multirow{2}{*}{ Keterangan } & \multicolumn{2}{c}{ Jenis karet } \\
\cline { 2 - 3 } & $\begin{array}{c}\text { Karet } \\
\text { unggul }(\mathrm{Kg})\end{array}$ & $\begin{array}{c}\text { Karet lokal } \\
(\mathrm{Kg})\end{array}$ \\
\hline Jumlah & 39304.5 & 18451.6 \\
Rata-rata & 935,82 & 439,32 \\
Standar deviasi & 333.75 & 141.59 \\
Koefisien variasi & 0.36 & 0.32 \\
\hline
\end{tabular}

Sumber data : Analisis Data Primer, 2015

Hasil analisis, menunjukan bahwa nilai koefisien variasi diperoleh yaitu $\mathrm{CV} 1=0,36 \geq$ $\mathrm{CV} 2=0,32$ yang artinya risiko produksi usahatani karet unggul pada tahun 2015 lebih besar atau sama dengan risiko produksi usahatani karet lokal pada tahun 2015. Bedanya terlalu tipis yaitu sebesar 0,04 jadi risiko produksi karet unggul dan karet lokal pada tahun 2015 tidak ada perbedaan. Dari hasil wawancara dengan petani karet ungul maupun karet lokal risiko produksi karet ungul dan karet lokal tidak berbeda karena dari pembibitan karet ungul yang mengunakan batang bawah dengan jenis GT 1 sedangkan batang atasnya PB 260, dari kedua jenis karet ini bisa melawan hama dan penyakit yang menyerang tanaman karet. Jadi risiko produksi tanaman karet ungul sama dengan risiko produksi karet lokal yang sudah beradaptasi dengan lingkunganya, dan yang tahan terhadap hama dan penyakit yang menyerang tanaman karet lokal.

\section{Uji T}

Uji $\mathrm{T}$ merupakan uji yang digunakan Untuk menguji perbedaan risiko produksi usahatani karet unggul dan karet lokal. Untuk dapat mengetahui secara jelas mengenai uji $\mathrm{T}$ dapat dilihat pada tabel 3 .

Tabel 3. Analisis Mean, Std. Deviation, Std. Error Mean dan Uji T-test Karet Unggul dan Karet Lokal

\begin{tabular}{lcc} 
Variabel & Karet Unggul & Karet Lokal \\
\hline $\mathrm{N}$ & 42 & 42 \\
\hline Mean & 935,83 & 439,32 \\
\hline Std,Deviation & 333,751 & 141,592 \\
\hline Std,Error Mean & 51,499 & 21,848 \\
\hline
\end{tabular}

Dapat dilihat dari tabel diatas karet unggul lebih banyak hasilnya dibandingkan karet lokal dapat dilihat pada kolom mean bahwa hasil produksi karet unggul yaitu 935,83 > 439,32 sudah terlihat jelas ada perbedaan antara hasil produksi karet unggul dan karet lokal.

Hasil analisis uji - T, pada karet unggul dan karet lokal dapat dilihat pada nilai mean difference yaitu sebesar 496,498 ini menunjukkan selisih rata-rata produksi antara usahatani karet unggul dan karet lokal.

\section{SIMPULAN}

Kesimpulan dari hasil penelitian mengenai Anaisis Risiko Produksi Usahatani Karet Unggul dan Karet Lokal di Desa Sekura Kecamatan Teluk Keramat Kabupaten Sambas adalah sebagai berikut:

1. Dari ketiga kelompok umur tanaman karet unggul maupun lokal yaitu kelompok (1) umur tanaman 15 dan 16 tahun, kelompok (2) umur tanaman 17 dan 18 tahun dan kelompok (3) 20 tahun hasil analisis perbandingan risiko di lihat dari nilai Coefisien Variasi (CV) yang paling berisiko adalah pada kelompok (3) umur tanaman karet 20 tahun. Dengan nilai koefisien variasi (CV) sebesar 0,57.

2. Risiko usahatani karet unggul dengan nilai koefisien variasi sebesar 0,36 sedangkan risiko usahatani karet lokal nilai koefisien variasinya sebesar 0,32 . Ini artinya risiko produksi karet unggul pada tahun 2015 lebih besar atau sama dengan risiko produksi karet lokal pada tahun 2015. Karena perbedaannya sangat tipis yaitu 0,04 jadi risiko produksi karet unggul dan karet lokal pada tahun 2015 tidak ada perbedaan.

3. Hasil analisis uji - T, pada karet unggul dan karet lokal dapat dilihat pada nilai mean difference yaitu sebesar 496,498 ini menunjukkan selisih rata-rata produksi antara usahatani karet unggul dan karet lokal. 


\section{DAFTAR PUSTAKA}

Anwar Chairil, 2001, Pusat Penelitian Karet, Medan. MIG Corp.

Setiawan Heru, Didit dan Agus Andoko, 2005. Petunjuk Lengkap Budidaya Karet.Cetakan I. Agro Media Pustaka, Jakarta.
Sugiyono, (2012), Metode Penelitian

Kuantitatif Kualitatif dan R\&D. Bandung: Alfabeta

Sugiyono, 2002, Statistik Untuk Peneliti, Alphabeta, Bandung

Wahyono, 2010, Sapta Bina Usahatani Karet Rakyat. Penebar Swadaya. Jakarta 